\title{
A Greek-Turkish peace project: assessing the effectiveness of interactive conflict resolution
}

\section{Esra Cuhadar, Orkun Genco Genc \& Andreas Kotelis}

To cite this article: Esra Cuhadar, Orkun Genco Genc \& Andreas Kotelis (2015): A Greek-Turkish peace project: assessing the effectiveness of interactive conflict resolution, Southeast European and Black Sea Studies, DOI: 10.1080/14683857.2015.1020141

To link to this article: http://dx.doi.org/10.1080/14683857.2015.1020141

\section{Published online: 07 Apr 2015.}

\section{Submit your article to this journal $\square$}

山 Article views: 74

Q View related articles ๘

View Crossmark data ¿ 


\title{
A Greek-Turkish peace project: assessing the effectiveness of interactive conflict resolution
}

\author{
Esra Cuhadar ${ }^{\mathrm{a}}$, Orkun Genco Genc ${ }^{\mathrm{b}}$ and Andreas Kotelis ${ }^{\mathrm{c} *}$ \\ ${ }^{a}$ Department of Political Science and Public Administration, Bilkent University, Ankara \\ Turkey; ${ }^{b}$ LinkedIn, Dublin, Ireland; ${ }^{c}$ Department of International Relations, Zirve \\ University, Gaziantep, Turkey
}

(Received 16 June 2014; accepted 10 February 2015)

\begin{abstract}
This paper evaluates a Greek-Turkish peace project, which was composed of three interactive workshops and was held with university students from Greece and Turkey. We evaluate the project by combining a two-way evaluation methodology. The first is a process evaluation where we examine the project's 'theory of change' through interviews with the organizers and participant observation. A theory of change map has been created as a result depicting the beliefs of the organizers about the conflict, the conditions they see as necessary to transform the conflict, the programmatic activities and macro-level goals. In the second part, we conduct an outcome evaluation measuring empathy and trust towards the members of the other ethnic group. We employ a two-group, post-test experimental design. The findings of this phase suggest that the participant group has significantly higher level of empathy and trust towards the other group than the non-participants. Finally, we compare the results from the two phases of evaluation and draw both practical lessons for peace practitioners and theoretical implications to guide future research.
\end{abstract}

Keywords: Greek-Turkish relations; peace and conflict studies; interactive conflict resolution; peace education; empathy; trust

\section{Introduction}

Greece and Turkey are involved in an intractable conflict since the beginning of the twentieth century. In spite of the various negotiated agreements, and the fact that at times the two states managed to normalize and improve their relations, not only the two states experienced occasional spurts of crises (e.g. 1974, 1987, 1996, 1999) that brought them to the brink of war, but also most of the disagreements are still looming and unresolved today. Intractable conflicts can be highly resistant to resolution, pervasive and destructive. They also involve well-entrenched hostile perceptions of the out-group, drag on for an extended period of time and are prone to escalation over and over again (Kriesberg, Northrup, and Thomson 1989; Coleman 2000).

In intractable conflicts, such as the Greek-Turkish one, traditional peacemaking mechanisms such as negotiation and power mediation often remain insufficient because changing the hostile attitudes and behaviours of people are also essential in order to transform the conflict. Hence, to complement such traditional peacemaking

*Corresponding author. Email: andreas.kotelis@zirve.edu.tr 
mechanisms, peace education workshops and interactive conflict resolution (ICR) workshops are also often employed. These workshops usually aim at reducing prejudice and negative stereotypes among group members, while, at the same time, they aim to increase trust levels and empathy among conflicting parties. This paper presents an in-depth analysis of such an ICR project held with Greek and Turkish university students in 2004 and 2005. Our research is one of the few empirical and systematic studies conducted on a Greek-Turkish workshop. It is comprised of a two-way evaluation strategy (process and outcome evaluation) and offers significant insights into the benefits of such workshops and their effectiveness, as well as some practical suggestions for future organizers and planners of similar ICR activities. As a result of this study, we found out that the project was successful in instigating higher trust and empathy between the participant university students and these effects were sustainable a year later. We also developed ideas as to how to fill the gap between the micro-level achievements in the project with macro-level objectives.

\section{Historical background of the Greek-Turkish conflict}

Our current understanding of the Greek-Turkish conflict involves an amalgam of several issues that are not necessarily connected to each other, but act accumulatively towards the worsening of the Greek-Turkish relations. Undoubtedly, the Cyprus problem, although an international and not a bilateral issue only, has been the biggest obstacle before normalization of relations and has always been the major source of deterioration in the relations between the two states. Another key issue in the conflict is related to the Aegean Sea. In particular, this problem is concerned with the delimitation of the continental shelf and/or the exclusive economic zone, the width of the territorial waters, the extend of the Greek air space and the flight information area over the Aegean, the demilitarization of the East Aegean islands by the Greek Army, and the NATO operational control in the Aegean Sea. Finally, the treatment and rights of the minorities have been a cause of friction between Turkey and Greece since the signing of the Lausanne Treaty between the two parties in 1923 (for a more detailed historical background on these issues, see Coufoudakis 1985, 1991; Bahcheli 1990; Clogg 1991; for a presentation of the legal arguments, see Syrigos 1998; Bolukbasi 2004; Heraclides 2010).

The most recent rapprochement started between Greece and Turkey in 1999 and led to significant improvement in relations (Ker-Lindsay 2000; Heraclides 2002; Evin 2004; Öniş and Yilmaz 2008; Tsarouhas 2009). However, the conflict is still volatile with minor military skirmishes and legal confrontation between the two countries especially at the European Court of Human Rights. Greek-Turkish conflict is fed by the well-entrenched negative attitudes in the society and by widespread enemy images towards the out-group (for an opinion poll, see Çarkoğlu and Kirişci 2004; for a recent Greek elites' view of Turkey, see Ifantis, Kotelis, and Triantafyllou, forthcoming). In intractable conflicts, attitudes and images are passed on from one generation to another with the help of the socialization agents in which an ethnocentric view of the past events is promoted and parties hardly communicate with each other directly (Bar-Tal 1997). The same pattern holds true for the Greek-Turkish conflict. Negative images and stereotypes are institutionalized with the help of various socialization agents such as the media, the Orthodox 
Church and the educational institutions (Millas 2000, 2004; Hadjipavlou 2003). Both sides hold on to their chosen traumas and glories in which the other is portrayed as the sole victimizer and the self as the sole victim and transfer these traumas to the forthcoming generations (Volkan 1991; Volkan and Itzkowitz 1994).

In order to achieve lasting peace between Greece and Turkey, tackling negative attitudes towards the 'other' is important, not only because a lasting peace requires more than peace agreements, but also because people are increasingly involved with critical political decisions. To this end, the 1999 rapprochement is characterized by the flourishing of track-II and multi-track initiatives that included a variety of actors from Turkish and Greek societies. Few of these initiatives, such as the Greek-Turkish Forum (Ozel 2004) and the Exploratory Talks, included high-level influentials and served as backchannel to official negotiations. Still, they dealt with some of the most important and unresolved issues still deciding the fate of the Greek-Turkish conflict. Most of these initiatives covered issues not directly related to the heart of the matter but rather tangential issues, such as tourism (e.g. a twoday conference in 2013 regarding cooperation on tourism with the participation of North Aegean Province Department of Tourism and the Association of Turkish Travel Agencies); education, business and trade cooperation (e.g. the GreekTurkish Business Forum); sports and arts (e.g. a recent Greek-Turkish painting exhibition from Democritus University and Trakya University); and journalists (e.g. Greek-Turkish Journalists Forum). ${ }^{1}$ As far as education is concerned, apart from the several workshops that included university students from both countries, cooperation was institutionalized by the establishment of several university departments specialized in the topic. The most significant of these efforts was the establishment of a Greek-Turkish relations focused graduate programme at Bilgi University, in cooperation with the Hellenic Foundation for European and Foreign Policy (ELIAMEP). (For a more detailed analysis of civil society cooperation, see Birden and Rumelili 2009).

\section{Evaluation of the Greek-Turkish peace workshop}

In this paper, we focus on a Greek-Turkish peace workshop (GTPW), which was composed of three interactive workshops and was held with 30 university students from Greece and Turkey. The project was organized jointly by one Turkish and one Greek think tank and was funded by a European Union grant. Each workshop was held with the same Turkish and Greek students and lasted for three days. The first workshop took place in Istanbul in November 2004, and the second and third took place in Athens in December 2004 and February 2005, respectively. The participants had a chance to interact with each other during the sessions discussing issues related to Greek-Turkish relations. They also had plenty of time to interact with each other in-between the sessions in their free time. During the sessions, they received lectures from various scholars on mediation, theories of peace and conflict, and the history of Turkish-Greek relations. As the final product, the organizers wanted the participants to come up with ethnically mixed teams and then each team to produce a paper that would deal with one of the problems that causes friction between Greece and Turkey. Those papers were presented during the final workshop. Students had many opportunities for contact and interaction during the workshops and in social activities. Social activities were an important part of the project and were composed of trips to historical sites. In-between the meetings, 
students continued to correspond with their team members and the organizers through email in order to work on their joint papers. In the last meeting, joint papers were presented and discussed by the whole group.

ICR or interactive peace workshops often have the goals of reducing inter-group prejudice and negative stereotyping, promoting inter-group empathy and understanding, building trust and creating awareness about the root causes of the conflict and about non-violence. Promoting and facilitating inter-group contact and educating the participants in various aspects of conflict and peacebuilding are among the common activities used in peace workshops in order to attain these goals. These workshops often put the victim and perpetrator into interchangeable roles and aims at transcending these views into an understanding of shared pain and shared empathy (Hadjipavlou 2007). Peace workshops ${ }^{2}$ most of the time take place at the grass roots level and target groups like young people. The practice is diverse, and however, the major outcomes of peace workshops can be summarized as follows according to Salomon: (1) legitimation of the other's collective narrative in a way that events can be seen from both lenses; (2) critical examination of the in-group's contribution to the conflict in which the parties are liberated from competition for sole victimhood; (3) develop empathy for suffering in order to appreciate other's pain and loss and generate mutual humanization; and (4) engagement in non-violent activities (Salomon 2002, as cited in Hadjipavlou 2007). Although building empathy is mentioned as a stand-alone outcome by Salomon, it can be further argued that the first two outcomes of the workshops - legitimation of the other's collective narrative and critical examination of the in-group's contribution to the conflict also require empathy and taking perspectives. Therefore, empathy and perspectivetaking can be considered as one of the key outcomes of the peace workshops. Generating empathy was emphasized as a critical outcome of the workshops by many other scholars in the literature (For example, see Kelman 1997; Maoz and Bar-On 2002; Malhotra and Liyanage 2005).

In practice, a variety of methods are used in peace workshops to achieve the outcomes listed above. Some of these methods, though not exclusive, are as follows: contact intervention, training of participants in conflict resolution skills such as mediation and negotiation (combined with contact or not), teaching of human rights curricula and training in non-violence philosophy. The Greek-Turkish project that we assess in this paper is a peace workshop that is primarily a contact intervention because it is based on social contact as a mechanism of attitude change. In addition to contact, secondarily it includes the teaching of skills and knowledge (i.e. mediation skills and lectures on the philosophy of peace and the history of Greek-Turkish relations).

Although the above-mentioned outcomes are often stated as expected outcomes by practitioners in peace workshops, scholarly research concerning their effects is scarce and is a newly emerging topic. Yet, systematic assessment of peace workshops, with respect to their design and implementation as well as their impact, contributes to the improvement of this tool and gives practitioners and funders a better idea about the conditions under which they are more effective.

There is often an assumption for peace workshops that empowering participants with skills and knowledge, combined with a setting in which there is friendly interaction and contact, will eventually result in changes in negative perceptions, attitudes and behaviours towards the other side. However, so far these assumptions and such workshops have been inadequately assessed. Only in the last decade, 
several studies focused on the assessment of peace workshops (Maoz 2000, 2004; Salomon 2002; Salomon and Kupermintz 2002; Malhotra and Liyanage 2005; Ohanyan and Lewis 2005). In interactive peace workshops, scholars identify two levels of goals and achievements: micro-level (i.e. inter-personal level including the immediate workshop participants) and the macro-level (i.e. the inter-group level or the societal level referring to the workshop effects beyond the immediate workshop participants) (for example, Mitchell 1993; Fisher 1997; Rouhanna 2000; D’Estrée et al. 2001). Existing evaluations mostly focus on the impact of workshops at the micro-level, their effect on the immediate participants, rather than the transfer of effects and outcomes or 'generalization' to the macro-level. While some of these studies focused on assessing changes in the cognitive domain (for instance Maoz 2000), few of them (for instance Malhotra and Liyanage 2005) focused on measuring impact in the affective and behavioural domains as well. Furthermore, very few studies so far focused on the question of sustainability of workshop effects (as examples, see Malhotra and Liyanage 2005; Rosen 2006). They found contradictory results in terms of the sustainability of effects.

Specifically concerning the Greek-Turkish context, there has been no systematic effort to date to assess the outcomes of the peace workshops. Yet, assessment in this context is not only needed to improve future practice, but also has important theoretical implications. Unlike some of the conflicts in which peace workshops were assessed, such as the Israeli-Palestinian or Georgian-Abkhaz conflicts, the Greek-Turkish conflict is not at a violent stage, and power asymmetry between the participants does not exist. Considering that power asymmetry between the participants affected the dynamics of previous peace workshops (Maoz 2004; Ohanyan and Lewis 2005), the Greek-Turkish case renders special attention.

To fill this gap, in this paper, we conduct a two-way evaluation methodology: a process and outcome evaluation. In the process evaluation, we focus on the design and implementation of the project. In the outcome evaluation, we measure empathy and trust as key outcomes, because as mentioned in the previous paragraph, empathy is a key outcome in peace workshops. Our study has been greatly inspired by Malhotra and Liyanage's assessment of a peace workshop in Sri Lanka, which focused on empathy (Malhotra and Liyanage 2005). Differently, in addition to empathy, we also measure the development of trust. Although not emphasized much by peace practitioners, unlike empathy, development of trust has been another key outcome in peace workshops and can even serve as a practical and strong basis for the parties to build a mutual and sustainable relationship and cooperation after the workshops. Ohanyan and Lewis showed in the context of Georgian-Abkhaz peace workshops that despite the minimal and asymmetrical changes in the attitudinal orientations of the participants, they were still willing to work jointly with the other side (Ohanyan and Lewis 2005). Development of trust therefore may be especially important when asymmetrical relations are the case, such as in the case of Georgian-Abkhaz or Israeli-Palestinian relations, in which the Abkhaz or the Palestinians may be more reluctant to develop empathy towards Georgians and Israelis, respectively (Maoz 2004; Ohanyan and Lewis 2005).

\section{Why multi-method assessment is necessary?}

There are two types of evaluation studies: formative (process) and summative (outcome) (Scriven 1967; Rossi, Lipsey, and Freeman 2004). Formative evaluations 
seek insights into ways to improve the intervention and focus on the evaluation of the process, whereas summative evaluations assess the intervention's quality and success in meeting its objectives and focus on outcome (Scriven 1967; Rossi, Lipsey, and Freeman 2004). Formative evaluation is especially useful during the process of goal setting and to understand how change is planned and linked to the series of activities which will deliver expected outcomes. On the other hand, summative evaluation is useful once the project is completed to answer questions such as: What has been achieved? and What has been sustained?

Most of the evaluation studies on peace workshops are outcome evaluations that assess the impact of the workshop on the immediate participants (the micro-level). At the micro-level, few studies carry out process evaluation (for instance, Rothman and Friedman 2002) and even less use a combination of process and outcome evaluation (an exception is Maoz 2000, 2004). So far, the researchers either carried out process evaluation alone to check the compatibility of goal-setting with the activities designed as in Rothman and Friedman's action evaluation framework (Rothman and Friedman 2002), or they only measured the acquisition of certain skills or degree of change in attitudes after a workshop without looking at the organizer's rationale for programme design and implementation as in the Malhotra and Liyanage's 2005 study of Sri Lankan workshops.

In this paper, we argue that combining process and outcome evaluations for assessment at the micro-level provides a better and more comprehensive strategy to assess peace workshops. While process evaluation helps us understand and map the 'theory of change' of the peace project, outcome evaluation is useful to find out what has been achieved at the end. By theory of change, we refer to the causal process through which change is designed in the programme, including how the organizers frame the problems to be addressed, their intervention goals, the processes through which change is anticipated, the programmatic activities to address these problems and the expected outcomes (Shapiro 2003). In other words, a theory of change asks the following question: Why do peace practitioners do things the way they choose to do? Therefore, at the end of a combined process and outcome evaluation, the researcher can compare the results of the two evaluations and suggest whether the workshop outcomes are compatible with the theory of change of the organizers or not.

Combining the two approaches of evaluation requires using multiple research methods. Process evaluation requires an in-depth understanding of the programme's and organizers' goals and rationales. Such in-depth analysis benefits from interviews with the organizers and also research on programme documents. It also requires participant observation during the workshops. Outcome evaluation benefits from experiments and surveys with participants as well as observation of participants during the sessions.

Combining the two evaluation approaches also requires significant resources. There are methodological difficulties already facing the researchers in evaluating peace workshops such as collecting data in conflict zones (see Cuhadar, Dayton, and Paffenholz 2008). In addition, there are difficulties emanating from the design of the peace workshops. For instance, often evaluation is not integrated into the programme from the beginning mostly due to lack of funding for external evaluators. Thus, reliable pretest data are often lacking because an evaluator is called upon at a later stage. Hence, researchers dealing with the evaluation of peace workshops often find themselves having to compromise from a perfect research 
design. Despite these difficulties, we think that evaluation of peace workshops is still worthwhile even with the limited data available and the constraints imposed on the researchers. Outcomes may not be as reliable, as in a strictly rigorous methodological design, but still evaluation of a peace workshop offers important pedagogical lessons.

We came across with similar problems as well and had to alter our original research plans. Despite these difficulties, we chose to undertake the assessment of GTPW and share our results with the scholarly community thinking that there are lessons that can be drawn simply from conducting an evaluation of a peace workshop, a rare endeavour in the field of peacebuilding. Because of our involvement in the project at a later stage, we did not have pretest data. Thus, we had to rely on a post-test only experimental design for outcome evaluation. Because most of the peace workshops are held with a small group of people, there are two additional methodological compromises. First, the number of observation points is limited. Second, since the participants are selected by the organizers and often evaluators are called in later, random assignment of subjects to groups is not possible. All of these constraints make collecting the ideal type of data on peace workshops a difficult enterprise. Given these constraints, using multiple methodologies that allow the evaluators to assess the process and outcome, triangulating data with multiple methods are even more important. Research opportunities in which a process and outcome evaluation can be combined are rare in the field. In sum, we took on this endeavour mainly for pedagogical purposes being aware of the methodological compromises we have to make.

For the process evaluation part, we first identified and mapped GTPW's 'theory of change' through interviews with the organizers, document analysis and participant observation. Then, we carried out a two groups (participant and nonparticipant) and post-test only experiment in which we measured the acquisition of trust and empathy by the workshop participants. Finally, we compare the findings from the two assessments to see which parts of the theory of change map are fulfilled in the project and what remains to be done.

\section{Results of process evaluation: mapping the GTPW's theory of change}

Process evaluation of the project identifies and maps its theory of change. The following interview questions were used in the interviews with the GTPW organizers. The same questions were used and tested previously with a series of Israeli-Palestinian peace practitioners in another project conducted by one of the authors in order to identify their programmes' 'theory of change'.

(1) What do you see is at the heart of the conflict? (to understand what the assumptions of the organizers are about the underlying/root causes of the conflict).

(2) Which aspects of the conflict did you choose to address? Why? (to understand the beliefs of the organizer about the conditions under which the root causes can be transformed.).

(3) What kind of activities did you plan to address the conflict? How (through what mechanisms) do you think these activities will lead to your desired outcomes? 
The interviews were held with four of the organizing committee members of the project. Both Turkish and Greek organizers were interviewed. In addition to the interviews, in order to answer the above listed questions, we studied the action plans and documents formulated prior to the project. These were provided to us by the Greek and Turkish organizers. Finally, one of the authors of this paper was a participant in the workshops and had the opportunity to observe and take notes. In addition, another author attended one of the three workshops. We should note that not all aspects of the program's theory of change were pre-planned and reflected upon by the organizers before the project started. In areas where the organizers did not do any pre-planning, we encouraged them to reflect on those aspects of their practice.

Based on the data gathered from interviews and project documents, we created a theory of change map of the project, inspired by the 'theory map' tool developed by Weiss $(1998,62)$. This map provides a picture of the intellectual landscape of the organizers showing the choices they made either intentionally or not. The theory of change map for the GTPW can be seen in Figure 1.

For the first question, the beliefs of the organizers about the root causes of the conflict, organizers mentioned that they see two main causes at the heart of the Greek-Turkish conflict. The first one is high politics (or power politics). In this regard, they emphasized the stalemate in Cyprus, which poses a threat and an obstacle to improving bilateral relations. However, the organizers indicated that the project chose not to focus on this cause. The second cause, the one that the project aimed to tackle, is related to the socialization processes in both countries. Organizers argued that Greeks and Turks have been socialized to view each other as enemies. This negative attitude towards the other has been reinforced throughout the years with lack of contact and closed channels of communication between the people. They suggested that lack of communication poses a threat to fruitful

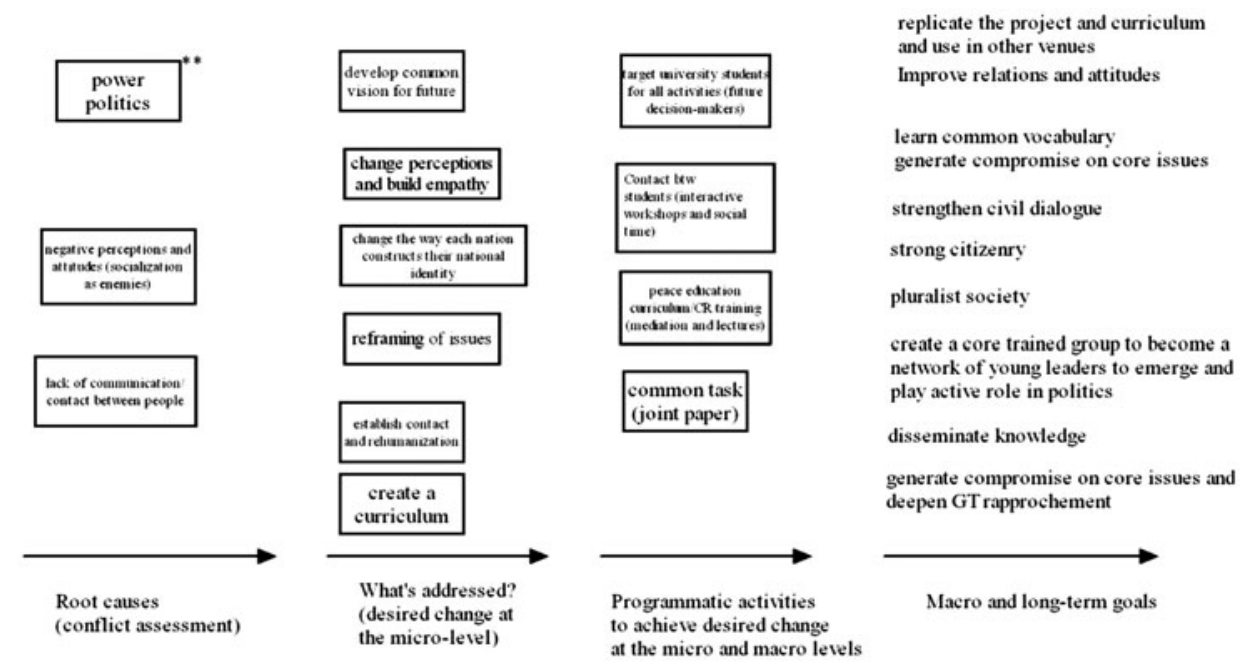

Figure 1. The 'Theory of Change' Map of the 'Project.

Source: **This root cause was not addressed in the project. ${ }^{\dagger}$ This was mentioned in the project proposal. 
dialogue. This is the specific underlying cause of the conflict that the organizers aimed to change with this project.

Regarding the conditions under which the organizers think the root causes can be transformed, they outlined three routes for positive change. These are as follows: (1) reframing the issues constituting the Turkish-Greek conflict; (2) changing the way, two groups view each other; and (3) changing the way, each nation constructs its national identity (e.g. changing the construction of one's identity based on a negative image of the other or based on the de-legitimization or de-humanization of the other). Additional conditions that can create change were mentioned by the organizers in their grant proposal. These were the need for a strong citizenry and a pluralist civil society, and a creating a network of young leaders to play a constructive role in the Greek-Turkish rapprochement. These latter goals, especially the first two, were set in the beginning of the project and were not necessarily incorporated into the project design and implementation. Since these are concerned more with the long-term objectives, in Figure 1, we mention them under the long-term/macro-goals.

In the theory of change map, we distinguish between desired change in the short-term and micro-level and change in the long-term and macro-level. Microlevel goals refer to those achieved with the immediate participants of the workshops in the short-term, whereas macro-level objectives can be achieved in the long-term and require additional work beyond the immediate participants to transfer the effects of the workshops. Such distinction between micro-level and macro-level and short-term and long-term was not formulated by the organizers, but was something we inferred from the interviews and our reading of the grant proposal.

Regarding the specific programme activities organizer planned in order to bring about the desired change(s), we were especially interested in whether the organizers linked the activities with the desired changes they mentioned.

We found that the project did not conceptualize the link between the project goals/conditions for change and project activities adequately. Note that, the activities planned by the project were three interactive workshops with university students, last one in the format of a mini-conference in which they presented their joint work on Greek-Turkish relations. Initially, the organizers did not elaborate on how each activity in the project (i.e. interactive workshops, lectures on peacebuilding and mediation, and joint papers) could help realize a certain goal. When we interviewed the organizers, we identified the activities and how each could bring about which desired change. We shared this information with the organizers as feedback. The interviews about the process and the feedback helped the organizers reflect upon their rationale for selecting these activities.

The first activity formulated was interactive workshops between the university students. The necessary conditions of a friendly and interactive setting were provided by the organizers as well as social activities outside the workshops. However, these conditions were met without necessarily an intentional choice.

The second activity included lectures on peacebuilding and conflict resolution which were offered for several hours by conflict resolution practitioners and/or university professors from Greece, Turkey and England. The lectures were on mediation, Greek-Turkish history and theories of international peace. For this activity too, the organizers did not specify why these issues were selected for lectures and how they decided about the number of lecture hours. 
The third activity was joint papers written in mixed Greek-Turkish groups on a topic concerning the Greek-Turkish conflict. Students worked on these papers inbetween the workshops, and they presented them to the whole group in the third workshop. The organizers envisioned these joint papers as the final and tangible outcome of the project. This activity was the most thoroughly planned activity among all three. The organizers had the idea that through the paper writing process, participants will reframe the Greek-Turkish issues jointly. In the first workshop, organizers came up with a list of issues concerning Turkish-Greek relations. The participants were then asked to pick topics, and the organizing committee formed the groups. Eleven groups were formed eventually studying topics such as civil society, earthquake diplomacy and the role of leadership in the conflict. The lectures were also thought to help students learn a common vocabulary to enable them to discuss these issues more constructively. This third activity at the end was also expected to lead to the learning of compromise on core issues in addition to contributing to the 'reframing' of the issues pertaining to Greek-Turkish conflict. Since reframing was one of the goals mentioned by the organizers for the first question, the route towards this goal was clearly articulated and thoroughly planned by the organizers unlike the other goals and activities in the project.

Overall, the GTPW conducted a basic conflict assessment and developed a set of project goals in line with this assessment. It also planned three types of activities within the project. They established a clear rationale regarding how the third activity (joint papers) fulfils their goal of reframing of the issues. However, for the other activities and goals, organizers did not necessarily provide a rationale for why these activities are selected and how these activities are expected to lead to the desired changes. They also did not provide a route to how the micro-level achievements will be connected to the macro-level. To further illustrate these gaps, we give the following examples.

The organizers used interactive workshops as the general context for all of the other activities. During the interviews, they mentioned 'workshops that bring university students together', without articulating the rationale for organizing an interactive workshop with university students and the possible pathways of change once these workshops are held. The organizers acted with an implicit assumption that interactive workshops would be helpful in opening channels of communication, improving relations and reaching mutual understanding between the parties as well as building a common vision for the future, which would ultimately lead to the emergence of a strong citizenry and pluralist civil society in both countries. They did not clearly articulate how interactive workshops would lead to all of these outcomes.

A similar situation existed for the third activity: writing joint papers. As mentioned earlier, this was an important activity which was successfully applied by the organizers and targeted one of the project goals openly. Besides helping students develop a common vocabulary and reframing the conflict, this activity encouraged the students to accomplish a common task and cooperate towards the achievement of this task. The students had to negotiate about the conflict while writing a joint paper and had to develop a common language in order to accomplish this task. This was a valuable learning experience and a successfully planned and implemented activity. However, even though the activity was successful and was highly relevant to one of the goals mentioned, like in the previous example, the organizers did not make this programmatic choice intentionally. Although they did things 
right, they did not mention the rationale for the activity's selection and the pathway of change during the interviews. Instead, the second activity 'peace education curriculum' was mentioned as the main activity in the proposal and in developing the Turkish-Greek rapprochement. However, which module/training/skill within the peace education curriculum would lead to the desired changes and how was not articulated and rather presented as a vague idea. Thus, the organizers planned and implemented activities successfully, but they were not necessarily aware of their connection to the goals/conditions and why they were successful and instead mentioned other activities in their proposal which were vague and not really implemented.

In sum, the organizers articulated their understanding of the causes of the conflict, the necessary conditions/changes in order to address the causes of the conflict and a set of programmatic activities, but they have not articulated what kind of programmatic interventions are expected to engender which of the expected changes and how they expect these changes to occur. Furthermore, among the numerous goals listed in the grant proposal, some were left without matching activities at the implementation stage. For example, although strong citizenry and pluralist civil society were mentioned as goals, they did not elaborate on how the planned set of activities could help move towards these macro-goals. The organizers acted with an assumption that the interactive workshops would automatically lead to the achievement of this goal. There was no plan or explanation as to how this could be realized or what follow-up activities would be necessary. This indicates another gap in the theory of change map: the link between the micro-goals and the macroobjectives was not elaborated. We further elaborate on this gap below.

A peace workshop like the GTPW often organizes and implements a set of activities at the micro-level only. Yet when asked what the project is trying to achieve, often times macro-level goals are mentioned by the organizers. In the GTPW too, organizers conducted activities targeting the micro-level only, but stated macro-level goals in their proposal such as achieving strong citizenry and pluralist civil society. Most of the time, the strategies to link the micro- and macro-levels (also called transfer from the micro-to-macro-level) are not articulated (for a definition and elaboration on transfer, see Fisher 1997). The GTPW also bears this gap commonly seen in the peace and conflict resolution practice. Achieving objectives at the macro-level would require planning of mechanisms and strategies. However, such mechanisms were not planned or implemented in the project. The reasons for their lack might be due to financial constraints or organizational difficulties. Still, coming up with a plan could be useful in terms of guiding other organizations working on the same conflict or in future projects. Without planning a transfer strategy, the macro-goals mentioned in the grant proposal become inflated expectations without firm grounding in micro-level activities.

The theory of change map in Figure 1 illustrates this gap as well. The left-hand side of the map refers to the micro-goals mentioned by the organizers in the interviews. We depict macro-level objectives mentioned in the written project proposal on the right-hand side of the map titled as 'macro and long-term goals'.

Following the process evaluation, we present the results from the outcome evaluation focusing on the assessment of changes in the participants. In this part, we focus on relational and attitudinal aspects, empathy and trust particularly, because as discussed in the process evaluation, the organizers mentioned negative attitudes and perceptions as one of the main causes of the Greek-Turkish conflict. The project 
aimed at changing negative attitudes and improving relationships. Finally, building of empathy is usually a key outcome of peace workshops. Empathy could serve as a key ingredient to achieve most of the project goals mentioned by the organizers such as ability to reframe issues jointly, improving relations and changing negative perceptions. Therefore, for the outcome (summative) evaluation, we focus on measuring the development of empathy and trust between the workshop participants. Towards this end, we conducted a post-test only experimental design.

\section{Summative evaluation: the method}

A post-test experiment with two groups was designed to measure the attitudes of the workshop participants with regard to trust and empathy vis-a-vis the other group. The experiment compared the levels of trust and empathy between the experimental (participants) and control groups (non-participants) less than a year after the project was completed. We recognize the weaknesses of a post-test only design that it does not allow us to measure robustly the degree of pre-disposition of the participants to dialogue before their participation in the project. This was due to our involvement in the project at a later stage as evaluators. In order to compensate for this weakness, similar to the Malhotra and Liyanage study, we wanted to introduce a third comparison group to our study composed of students who applied to the programme but were not selected as participants. Although organizers initially agreed to provide this information, it turned out that this information was not organized adequately to meet our purposes. Therefore, due to the limitations, we proceeded with a post-test design, but introduced a control group. The hypotheses that are tested are as follows:

Hypothesis 1: Students who met through the workshop experience have greater trust in members of the other ethnic group than do non-participants.

Hypothesis 2: Students who met through the workshop experience have greater empathy towards the members of the other ethnic group than do non-participants.

\section{Participants}

The total number of students who took part in the study was 60 . The number of students that participated in the workshops was 30. All of the participants were either senior undergraduates or junior graduate students whose average age was 24 . The participants were selected by the organizers in a way that the group includes an equal number of students from both genders and nationalities. Fifteen Greek and Fifteen Turkish students were selected of which $46 \%$ of the group was female participants and 54\% male participants.

The participants were selected by the organizers following a written application and a personal interview conducted by either the Greek or the Turkish organizer. There were fifty applicants in Greece and twenty in Turkey. Applicants were evaluated based on their English proficiency and basic knowledge of Greek-Turkish relations. The majority of the participants were selected from social science departments of several well-known universities.

The control group for this study was also comprised of 30 students who were again either senior undergraduates or junior graduates. The group was formed to resemble the same average age, nationality and gender proportions of the 
Table 1. Demographics of the participant and non-participant groups.

\begin{tabular}{lccc}
\hline & Participant (\%) & Non-participant (\%) & Total (\%) \\
\hline Greek students & 46.2 & 50 & 48.3 \\
Turkish students & 53.8 & 50 & 51.7 \\
Male students & 53.8 & 50 & 51.7 \\
Female students & 46.2 & 50 & 48.3 \\
\hline
\end{tabular}

participant group. These students were randomly selected from the same universities from which the participant students came, making sure that the educational (curriculum) and socio-economic background was similar. Table 1 summarizes the distribution of gender and ethnicity within the participant and non-participant groups.

\section{Measures and procedure}

The questionnaires measuring the level of empathy and trust were distributed to all 60 participants of the study by the author who was a workshop participant. We also asked the help of the organizers to gain access to the participants. Non-participant group was randomly selected from the same universities as the participant group. We sought the help of a local graduate student in Greece to recruit subjects for the non-participant group. For either group, the respondents did not know about the other group. The questionnaires were returned in a way to guarantee anonymity. At the end, four questionnaires either were not returned or were not usable. The total number of questionnaires taken into consideration for the analysis was 56.

The questionnaire included statements about trust (first 15 questions), empathy (following 5 questions) and a series of demographic questions. A five-point Likert scale was used for measurement, ranging from strongly agree to strongly disagree (1 referring to strongly disagree and 5 referring to strongly agree).

To measure trust, we used the inter-personal trust scale developed by Lewicki and Stevenson and modified the questions according to the Greek-Turkish context (Lewicki and Stevenson 1999). Lewicki and Stevenson defined a model identifying three different types of trust: calculus based, knowledge based and identification based. Their trust questionnaire includes questions on all of these types of trust. Calculus-based trust means that individuals develop some degree of confidence that "people will do what they say they are going to do". Knowledge-based trust means knowing the other well enough that allows you to anticipate his behaviour. Finally, identification-based trust is based on a complete empathy with or identification with the other party's desires and intentions (Lewicki and Stevenson 1999). In this paper, we do not report the results separately for each type of trust; instead, we report the overall trust scores.

To measure empathy, we used the empathy scale used by Malhotra and Liyanage to measure change in attitudinal empathy as a result of peace workshops conducted in Sri Lanka. Since the context and the type of intervention were very similar, we used the same empathy measures in this study. They adopted this scale from Davis" "empathic concern" (EC) subscale of the Interpersonal Reactivity Index which was designed to measure the degree to which a person has concern for the other's well-being (Malhotra and Liyanage 2005). It should be noted that 
empathy has a much richer and wider meaning especially as far as communication and psychology literature are concerned. Nonetheless, as Broome points out, the evolution of the term had less conceptual development in the field of conflict resolution (Broome 1993). Although many conflict resolution practitioners and scholars highlight the importance of empathy, being sensitive to the concerns of the other is the most common use of the term. Hence, we strongly believe that the Davis' EC subscale fits the purposes of our study. We adapted the questions according to the Greek-Turkish context by replacing Sinhalese and Tamil identities with Greek and Turkish. However, there is a slight difference between the questionnaire used by Maltotra and Liyanage and the one employed in this research in the sense that they used a 7-point Likert scale, while we used a 5-point Likert scale in order to make empathy measures compatible with those in the trust scale. There are five statements in this section of the questionnaire regarding empathy. Appendix 1 contains a copy of the questionnaire including both trust and empathy statements used in this study.

Malhotra and Liyanage in their study of a peace workshop in Sri Lanka also included a behavioural measure of empathy in addition to the attitudinal measure. They paid the participants and asked how much of this money they would donate for a fund-raising to help poor children of the other ethnicity (Malhotra and Liyanage 2005). They recorded the amount each participant was willing to pay. In our study, initially, we designed a similar behavioural measure using a scenario concerning donation for earthquake victims in the other country. This question remained as a hypothetical question as we did not pay the participants, thus not an adequate measure of behaviour. We do not report on this finding in this paper, but the participant group's average was higher than that of non-participants on that measure.

\section{Results}

We conducted $t$-tests for independent samples as well as regression analysis to analyse the data. Both analyses showed that the participants of the workshops have significantly greater degrees of trust and empathy towards the other ethnic group than the non-participants. Below, we only report the results of the regression analysis for first on trust, second on empathy.

Our first hypothesis which stated that students who met through the workshop experience have greater trust in members of the other ethnic group than do non-participants is supported. We conducted a regression analysis in which the participant and non-participant groups were treated as the independent variable (labelled as Group), and gender and ethnicity were control variables. Trust was the dependent variable. Table 2 reveals the results of the regression analysis regarding trust.

Table 2 indicates that there is a significant effect only concerning group $(p<.05, \beta=.351)$ Thus, the level of trust is significantly higher in the participant group, and also, there is no significant effect for ethnicity and gender regarding the levels of trust. It can be also inferred that trust has improved for both Greeks and Turks symmetrically, since the effect of ethnicity on the dependent variable is not significant. Unfortunately, as the data are based on a Likert scale questionnaire, the authors are unable to provide any illustrative examples on how the increased levels of trust were specifically expressed by the participants. 
Table 2. Trust towards the members of the other ethnic group.

\begin{tabular}{lc}
\hline Variables & Trust $(\beta)$ \\
\hline Group* & $.351(.142)$ \\
Gender & $.144(.142)$ \\
Ethnicity & $.230(.142)$ \\
\hline
\end{tabular}

Note: Regression for trust as dependent variable.

${ }^{*} p<.05$ (Standard errors in parentheses).

Table 3. Empathy towards the members of the other group.

\begin{tabular}{lr}
\hline Variables & Empathy $(\beta)$ \\
\hline Group* & $.330(.157)$ \\
Gender & $-.075(.156)$ \\
Ethnicity & $-.204(.156)$ \\
\hline
\end{tabular}

Note: Regression for empathy as dependent variable.

${ }^{*} p<.05$ (Standard errors in parentheses).

Concerning empathy, the regression analysis was used again to see the effects of group, gender and ethnicity on empathy as the dependent variable. The results are similar to trust and are presented in Table 3.

Like trust, the effect of group on empathy is positive and significant $(\beta=.330$, $p<.05)$, whereas other variables do not have significant effect on empathy. Participants of the workshop are significantly more empathetic towards the members of the other group than non-participants. Therefore, our second hypothesis concerning empathy is supported as well. Plus, empathy has symmetrically developed for the Greek and the Turkish groups since ethnicity again does not have a significant effect on the dependent variable.

The results of the post-test-only study support both of our hypotheses. The participants of the workshops portrayed significantly higher levels of trust and empathy towards the members of the other national group. Thus, the workshops made a contribution to the development of positive attitudes towards the other group at the micro-level and have become successful in fulfilling this micro-goal. Furthermore, empathy and trust improved symmetrically for both the Greek and Turkish groups since ethnicity did not have a significant effect.

\section{Comparing the results of the outcome evaluation and the theory of change map}

Having looked at the results of process and outcome evaluation separately, how does each evaluation inform the other? What are the implications of this study for the practice and theory of peace workshops?

Regarding the beliefs of the organizers about the root causes of the conflict and their desired changes, the outcome evaluation results suggest that the root causes of 'negative perceptions and attitudes' and 'lack of communication and contact between people' are successfully addressed in this intervention. Some of the desired changes - changing perceptions and building empathy, establishing contact and re-humanization, and reframing of issues - are also achieved successfully. The project succeeded in improving trust and empathy towards the other ethnic group. 
On the other hand, the following points call for attention and need future planning and additional self-reflection.

The organizers were not clear about the mechanisms of change and what they achieved in this intervention despite they created the necessary mechanisms. In other words, they did some things right but they need to reflect on why these things were right and how did they lead to right outcomes. For instance, even though certain conditions for an effective project, like the setting of the interactive workshops or the joint paper assignment, were present in the project, these were not planned intentionally by the organizers. The activities that were implemented in the project were not operationalized. While all of these activities were thrown into the project, the organizers were not clear about which activity tackles which goal and how. They assumed that the laundry list of activities will somehow all work together. This shows that the project lacked an essential theoretical framework on the following concepts: contact and peace education.

While the project organizers mentioned a vague idea of peace education curriculum in their project proposal, actually the main mechanisms of change used in the workshops were interactive workshops (contact) and working on a common task. The project organizers over-emphasized the lectures and the curriculum part in their grant proposal, while the interactive workshops were not planned in detail. Yet, given the poor content of the peace education component (constituting of a half day lecture on mediation, several lectures on international relations theories and Greek-Turkish conflict) marked with the lack of a proper curriculum and training agenda, interactive workshops and the student work on joint papers as well as the social time spent together were most likely the main mechanisms that led to an improvement in trust and empathy. However, when everything is used in combination, it is hard to identify which intervention led to what outcome. The organizers need to specify how successfully this curriculum is integrated into their intervention and also reflect upon whether the curriculum they want to design could be successful without interactive workshops at all. The curriculum used in the meetings was dominated by International Relations and History disciplines. It is not very likely that these lectures were instrumental in contributing to the improvement of empathy and trust because almost all of the students came from social science disciplines and were already exposed to this kind of material. Future research in this area is needed in better coordination with practitioners to sort out the possible different outcomes of different types of intervention to determine which is more effective.

The second important point that can be drawn from the comparison of the two evaluations is the following. One of the important assumptions of the organizers about the root causes of the conflict has been lack of communication and contact between people. They argued that such lack of communication and contact feed into the negative perceptions and attitudes. The project successfully addressed this root cause of the conflict. The organizers partially addressed the second root cause too: socialization into enemy images and stereotypes. However, the organizers did not address how this particular intervention could address more systematic mechanisms of socialization. One remedy to this could be what the organizers called as the 'emergence of a network of young leaders to play active role in politics', which is a macro-level and a long-term goal. How can this be realized is not planned though. The organizers could have discussed the future steps with the group towards fulfilling these macro-goals and to spread the effects of the micro-level workshop to the macro-level. Based on the process evaluation and the results of 
the experiment, it can be argued that the organizers need to undertake further planning that focus on macro-goals and linking them with the micro-goals. At the moment, the links between these levels are not elaborated adequately. Finally, a more systematic design for the peace education curriculum is needed, if the organizers will keep to their macro-goal of development of a curriculum.

A third important point is that the achievements of the project at the micro-level are overshadowed by the inflation of macro-goals mentioned in the grant proposal. The activity is successful, but when one looks at the project proposal, these achievements are overshadowed by very ambitious and vague macro-goals.

Finally, the following can be said to practitioners while planning their interventions of similar nature. Preparing a theory of change map, as in Figure 1, can be a useful planning instrument for the organizers. A map designed before carrying out an intervention helps the organizers see the gaps, expectations and the timeline for their desired changes in a more clear way. Furthermore, such a map will also be useful for outside evaluators both during the planning stage and in ex-post evaluation. The map we presented in Figure 1 can be illustrative and exemplary in this sense.

\section{Conclusion and ideas for future research}

The results of the current study suggest that positive effects relating to the development of trust and empathy among the participants were the most significant accomplishment of the GTPW analysed in depth in this study. Given our compromise in research design, due to the restrictions in the availability of data, we believe it would be necessary to conduct further systematic evaluation studies on similar initiatives. Future research needs to measure more robustly for the effects of pre-disposition of participants to dialogue using pretest data. Naturally, designing such an evaluation requires very close and early on collaboration with the organizers.

Another important remark is that, in order to be able to identify which action relates to which outcome, future research on peace workshops needs to measure the effects of interactive workshops, curriculum (lectures) and working towards a common task (joint paper) separately. In this study, we conjecture that the successful outcome was due to interactive workshops and working towards a common task (joint papers) rather than the short lectures given by various scholars based on our participant observation notes and informal conversations with the participants. However, in projects where these activities are used in isolation, the effect of each needs to be tested separately.

Finally, in our outcome evaluation measuring empathy and trust, we did not find any asymmetrical results for Greeks and Turks. This is contradictory with some of the other findings from peace workshops (e.g. among Israelis and Palestinians) where there is apparent power asymmetry. Future comparative research is needed in this regard in order to say something more definitive about the effectiveness of peace workshops in asymmetrical settings as opposed to more symmetrical settings. The success of this peace workshop may be due to the fact that it took place in a highly equal environment rather than a conflict characterized with asymmetry.

\section{Acknowlegdements}

The authors would like to thank Nimet Beriker, Benjamin Broome, Ali Carkoglu, Daniel Druckman, Ahmet Evin, and Philippos Savvides and the two anonymous referees for their 
insights and contributions to the various phases of this project. We are grateful to the Greek and Turkish organizers and the participants of the project for their willingness to share information with us on the project and their participation in the study.

\section{Notes}

1. For an online inventory of such grass roots initiates, see www.greekturkishnews.org. Also, see Kotelis (2006) for a detailed study of the Greek-Turkish Forum and the Greek-Turkish Journalists Forum.

2. Unlike ICR, which can be undertaken with decision-makers, elite and influential people, peace workshops are most of the time held with grass roots people. The term interactive peace workshop will be used in this paper to refer to those interactive activities held with grass roots people with the aim of improving relations between them and changing their negative attitudes towards each other. Such activities may also be called as peace education workshops in the literature.

\section{Notes on contributors}

Esra Cuhadar is an assistant professor at the Department of Political Science and Public Administration in Bilkent University, Ankara, Turkey. She was a Fulbright Visiting Scholar at Fletcher School of Law and Diplomacy at Tufts University during the 2011-2012 academic year. Her research interests include international mediation, interactive conflict resolution workshops, evaluation of peacebuilding and conflict resolution programmes, negotiation and mediation pedagogy and teaching, and foreign policy decision-making. Her research appeared in academic journals such as Negotiation Journal, International Negotiation, Journal of Peace Research, Computers in Human Behavior, Mediterranean Politics, International Studies Perspectives, Turkish Studies and Perceptions, and also in various book chapters. She completed a manuscript in 2012 with Burcu Gultekin-Punsmann, which was published by TEPAV and titled Reflecting on the two decades of bridging the divide: Taking stock of Turkish-Armenian civil society activities.

Orkun Genco Genc holds an MA degree in Conflict Analysis and Resolution from Sabanci University, in Istanbul, Turkey. In his early professional career, he started as a P2P selling consultant, while currently, he is working for LinkedIn as a Relationship Manager with the basic duty to help his customers have a positive experience with the LinkedIn products they purchased.

Andreas Kotelis is an assistant professor of International Relations at Zirve University in Gaziantep, Turkey. He teaches Conflict Analysis, International Negotiation and Mediation, Mediation in Law as well as core International Relations courses. He holds a $\mathrm{PhD}$ from Bilkent University, Ankara in Political Science and an MA in Conflict Analysis and Resolution from Sabanci University, Istanbul. His research interests focus on Greek-Turkish relations, Turkish Foreign Policy and Conflict Analysis and Resolution. His current research also includes issues relating to the refugee situation in Gaziantep, as well as the cooperation between the INGOs working in the area with the Turkish government. He has published in academic journals such as Turkish Studies and Turkish Review.

\section{References}

Bahcheli, T. 1990. Greek-Turkish relations since 1955. Boulder: Westview Press.

Bar-Tal, D. 1997. Formation and change of ethnic and national stereotypes: An integrative model. International Journal of Intercultural Relations 21, no. 4: 491-523.

Birden, R., and B. Rumelili. 2009. Rapprochement at the grassroots: How far can civil society engagement go? In In the long shadow of Europe: Greeks and Turks in the Era of postnationalism, eds. Othon Anastasakis, Kalypso Nikolaidis, and Kerem Oktem, 315-30. Leiden: Martinus Nijhoff. 
Bolukbasi, D. 2004. Turkey and Greece the Aegean disputes: A unique case of international law. London: Cavendish Pub.

Broome, B. 1993. Managing differences in conflict resolution: The role of relational empathy. In Conflict resolution theory and practice: Integration and application, eds. Dennis Sandole and Hugo van der Merwe, 97-111. Manchester: Manchester University Press.

Çarkoğlu, A., and K. Kirişci. 2004. The view from Turkey: Perceptions of Greeks and Greek-Turkish rapprochement by the Turkish public. Turkish Studies 5, no. 1: 117-53.

Clogg, R. 1991. Greek-Turkish relations in the post-1974 period. In The Greek-Turkish conflict in the 1990s: Domestic and external influences, ed. Dimitri Constas, 12-25. London: McMillan.

Coleman, P. 2000. Intractable conflict. In The handbook of conflict resolution, eds. Morton Deutch and Peter Coleman, 428-50. San Francisco, CA: Jossey Bass.

Coufoudakis, V. 1985. Greek-Turkish relations 1973-1983: The view from Athens. International Security 9, no. 4: 185-217.

Coufoudakis, V. 1991. Greek political party attitudes towards Turkey: 1974-1989. In The Greek-Turkish conflict in the 1990s: Domestic and external influences, ed. Dimitri Constas, 40-56. London: McMillan.

Cuhadar, E., B. Dayton, and T. Paffenholz. 2008. Evaluation in conflict resolution and peacebuilding. In $A$ handbook of conflict analysis and resolution, eds. Sean Byrne, Dennis Sandole, Ingrid Sadnole-Staroste, and Jessica Senehi, 293-7. London: Routledge.

D'Estrée, T.P., et al., 2001. Changing the debate about "success" in conflict resolution efforts. Negotiation Journal 17, no. 2: 101-13.

Evin, A. 2004. Changing Greek perspectives on Turkey: An assessment of the post-earthquake rapprochement. Turkish Studies 5, no. 1: 4-20.

Fisher, R. 1997. Interactive conflict resolution. Syracuse, NY: Syracuse University Press.

Hadjipavlou, M. 2003. Inter-ethnic stereotypes, neighborliness, and separation: Paradoxes and challenges in Cyprus. Journal of Mediterranean Studies 13, no. 2: 340-60.

Hadjipavlou, M. 2007. Multiple realities and the role of peace education in deep-rooted conflicts: The case of Cyprus. In Addressing ethnic conflict through peace education, eds. Zvi Bekerman and Claire McGlynn, 35-48. New York: Palgrave McMillan.

Heraclides, A. 2002. Greek-Turkish relations from discord to détente: A preliminary evaluation. Review of International Affairs 1, no. 3: 17-32.

Heraclides, A. 2010. The Greek-Turkish conflict in the Aegean. Basingstoke: Palgrave Macmillan.

Ifantis, K., A. Kotelis, and D. Triantafyllou. Forthcoming. National role and foreign policy: An exploratory study of Greek Elites' Perceptions towards Turkey. GreeSE: Hellenic Observatory Papers on Greece and Southeast Europe.

Kelman, H. 1997. Social-psychological dimensions of international conflict. In Peacemaking in international conflict, eds. William Zartman and Lewis Rasmussen, 191-238. Washington, DC: USIP Press.

Ker-Lindsay, J. 2000. Greek-Turkish rapprochement: The impact of 'disaster diplomacy'? Cambridge Review of International Affairs 14, no. 1: 215-32.

Kotelis, Andreas. 2006. Cognitive and relational outcomes of track-two initiatives and transfer strategies used: The cases of the Greek-Turkish forum and the Greek-Turkish journalists'conference. MA thesis, Sabanci University.

Kriesberg, L., T. Northrup, and S. Thomson. 1989. Intractable conflicts and their transformation. Syracuse, NY: Syracuse University Press.

Lewicki, R.J., M. Stevenson. 1999. The trust scale. In Negotiation: Readings, exercises and cases, 3rd ed., eds. Roy. J. Lewicki, David M. Saunders, and John Minton, 710-13. Boston, MA: Irwin/McGraw-Hill.

Malhotra, D., and S. Liyanage. 2005. Long-term effects of peace workshops in protracted conflicts. Journal of Conflict Resolution 49, no. 6: 908-24.

Maoz, I. 2000. An experiment in peace: Reconciliation-aimed workshops of Jewish-Israeli and Palestinian youth. Journal of Peace Research 37, no. 6: 721-36.

Maoz, I. 2004. Coexistence is in the eye of the beholder: Evaluating intergroup encounter interventions between Jews and Arabs in Israel. Journal of Social Issues 60, no. 2: 437-52. 
Maoz, I., and D. Bar-On. 2002. From working through the holocaust to current ethnic conflicts: Evaluating the TRT group workshop in Hamburg. Group 26, no. 1: 29-48.

Millas, H. 2000. Turk Romani ve Oteki: Ulusal Kimlikte Yunan Imaji [Turkish novel and the other: Greek image in the national identity]. Istanbul: Sabanci University Publications.

Millas, H. 2004. National perceptions of the 'other' and the persistence of some images. In Turkish-Greek relations: The security dilemma in the Aegean, eds. Mustafa Aydin and Kosta Ifantis, 53-66. London: Routledge.

Mitchell, C. 1993. Problem solving exercises and theories of conflict resolution. In Conflict resolution: Theory and practice, eds. Dennis Sandole and Hugo van der Merwe, 78-94. Manchester: Manchester University Press.

Ohanyan, A., and J. Lewis. 2005. Politics of peace-building: Critical evaluation of interethnic contact and peace education in Georgian-Abkhaz peace camp, 1998-2002. Peace and Change 30, no. 1: 57-84.

Öniş, Z., and Şuhnaz Yilmaz. 2008. Greek-Turkish rapprochement: Rhetoric or reality? Political Science Quarterly 123, no. 1: 123-49.

Ozel, S. 2004. Rapprochement on the non-governmental level: The story of the Turkish-Greek forum. In Turkish-Greek relations: The security dilemma in the Aegean, eds. Mustafa Aydin and Kosta Ifantis, 269-90. London: Routledge.

Rosen, Yigal. 2006. Does peace education in the regions of intractable conflict can change core beliefs of youth? Paper presented at the International Conference on Education for Peace and Democracy, November 2006, in Antalya, Turkey.

Rossi, P., M. Lipsey, and H. Freeman. 2004. Evaluation: A systematic approach. Thousand Oaks: Sage.

Rothman, J., and V. Friedman. 2002. Action evaluation for conflict management organizations and projects. In Second Track/Citizens' diplomacy: Concepts and techniques for conflict transformation, eds. John Davies and Edward (Edy) Kaufman, 285-98. Lanham, MD: Rowman and Littlefield.

Rouhanna, N. 2000. Interactive conflict resolution: Issues in theory, methodology, and evaluation. In International conflict resolution after the Cold War eds. Paul Stern and Daniel Druckman, 294-337. Washington, DC: National Academy Press.

Salomon, G. 2002. The nature of peace education: Not all programs are created equal. In Peace education, the concept, principles, and practice around the world, eds. Gavriel Salomon and Baruch Nevo, 3-13. Manhaw, NJ: Lawrence Erlbaum Associates.

Salomon, G., and H. Kupermintz. 2002. The evaluation of peace education programs: Main considerations and criteria for evaluation. Haifa: The Center for Research on Peace Education, University of Haifa.

Scriven, M. 1967. The methodology of evaluation. In Perspectives of curriculum evaluation eds. Ralph W. Tyler, Robert M. Gagne, and Michael Scriven, 39-83. Chicago, IL: Rand McNally.

Shapiro, I. 2003. Theories of change. In Beyond intractability eds. Guy Burgess and Heidi Burgess, Boulder: Conflict Research Consortium, University of Colorado. http://www.be yondintractability.org/essay/theories-of-change.

Syrigos, A. 1998. The status of the Aegean Sea according to international law. Athens: Sakkoulas/Bruylant.

Tsarouhas, D. 2009. The political economy of Greek-Turkish relations. Southeast European and Black Sea Studies 9, no. 1: 39-57.

Volkan, V. 1991. On chosen trauma. Mind and Human Interaction 4: 3-19.

Volkan, V., and N. Itzkowitz. 1994. Turks and Greeks: neighbors in conflict. Cambridgeshire: Eothen Press.

Weiss, C. 1998. Evaluation methods for studying programs and policies. Upper Saddle River, NJ: Prentice Hall. 


\section{Appendix 1. Questionnaire}

Age:

Gender:

Have you ever been in Greece (Turkey) before this workshop:

Have you ever interacted with a Greek (Turk) before this workshop:

Latest school graduated (or will graduate) from:

Answered on a scale from 1 (strongly disagree) to 5 (strongly agree):

(1) The way Greeks (Turks) behave does not bother me.

(2) Greeks (Turks) are known as people who keep their promises and commitments.

(3) Greeks (Turks) know that maintaining trust is more valuable than destroying it.

(4) Greeks (Turks) do what they say they will do.

(5) I hear about the good 'reputation' of Greeks (Turks) in keeping their promises.

(6) I have interacted with Greeks (Turks) a lot.

(7) I think I really know Greeks (Turks).

(8) I can accurately predict what Greeks (Turks) will do.

(9) I think I know pretty well what Greek (Turk) reactions will be to events.

(10) Greeks and Turks have a lot of common interests.

(11) Turks and Greeks share the same basic values.

(12) Turks and Greeks have a lot of commonalities.

(13) Greeks and Turks pursue many common objectives.

(14) I know that Greeks (Turks) would do whatever we would do if we were in the same situation.

(15) Greeks and Turks stand for the same basic things.

(16) I would get very angry if I saw a Greek (Turk) being ill-treated.

(17) I can not continue to feel okay if a Greek (Turkish) person next to me is upset.

(18) It upsets and bothers me to see a Greek (Turkish) person who is helpless and in need.

(19) I can understand how certain political issues might upset Greek (Turkish) people very much.

(20) I would get emotionally involved if a Greek (Turkish) person that I knew were having problems. 